\title{
Tuberculosis de la pared torácica en hemodiálisis: a propósito de un caso
}

\author{
Ma Soledad Lecueder*, Andrés Urrestarazú, Patricia Domínguez, Martín López y Asunción Álvarez \\ Servicio de Nefrología, Sanatorio Casa de Galicia, Montevideo, Uruguay
}

\section{Resumen}

Se describe el caso clínico de un paciente masculino de 42 años con enfermedad renal crónica en tratamiento sustitutivo de la función renal mediante hemodiálisis; el sujeto se presenta con una tumoración palpable con estudio imagenológico y microbiológico consistente con infección por Mycobacterium tuberculosis de la pared torácica y compromiso costal. La incidencia de tuberculosis en pacientes en hemodiálisis es ocho veces mayor y tiene el doble de mortalidad que la población general. En conclusión, dada la elevada incidencia de tuberculosis en el medio y en pacientes con hemodiálisis, debe mantenerse un alto índice de sospecha para establecer el diagnóstico. El tratamiento antibiótico combinado y el drenaje quirúrgico temprano son los pilares terapéuticos.

Palabras clave: Enfermedad renal crónica. Hemodiálisis. Tuberculosis extrapulmonar.

\section{Thoracic wall tuberculosis, in relation to a clinical case}

\section{Abstract}

Description of a clinical case. We describe a 42 years old male with chronic kidney disease on hemodialysis, with clinical presentation of a palpable tumor, whose imaging, and microbiological study were compatible with infection with Mycobacterium tuberculosis, extra-pulmonary thoracic wall, with bone involvement. The incidence of tuberculosis in patients on hemodialysis is eight times the general population and has double mortality. Conclusion: Given the high incidence of tuberculosis in our region and in patients on hemodialysis, where we can see atypical locations, we should have high suspicion for this diagnosis. Combined medical treatment and early surgical approach are the standard of care.

Key words: Chronic kidney disease. Hemodialysis. Extra-pulmonary tuberculosis.

\section{Introducción}

La tuberculosis (TB) es todavía la enfermedad infecciosa más letal del mundo. Según datos de la Organización Mundial de la Salud (OMS, 2018), la enfermedad tiene una incidencia mundial de 132 nuevos casos/reinfecciones por
100,000 habitantes, con una mortalidad $19.3 / 100,000$ habitantes. En cuanto a las Américas, la incidencia es de 29 casos nuevos/reinfecciones por 100,000 habitantes, con una mortalidad de 2.29/100,000 habitantes ${ }^{1}$, que representa el $3 \%$ de los casos mundiales.
Correspondencia:

*Mํㅗㄴ Soledad Lecueder

E-mail: solelecueder@gmail.com
Disponible en internet: 17-12-2020

Nefro Latinoam. 2020;17:113-116 www.nefrologialatinoamericana.com 
En Uruguay, con base en datos de la Comisión Honoraria para la Lucha Antituberculosa y Enfermedades Prevalentes, la incidencia de TB en la población general mantiene un crecimiento continuo desde el año 2006; la incidencia en 2018 era de 28.5 nuevos casos y recaídas por cada 100,000 habitantes ${ }^{2}$. Perú posee una incidencia de $135 / 100,000$, Brasil de $36.3 / 100,000$ y Argentina de 24.4/100,000 habitantes.

Un estudio nacional retrospectivo de 18 años (19952013), que utilizó datos del Registro Uruguayo de Diálisis y de la Comisión Honoraria para la Lucha Antituberculosa y Enfermedades Prevalentes, que incluyó a 10,516 pacientes en tratamiento sustitutivo renal con 13,083 casos de tuberculosis diagnosticados, demostró que la incidencia de TB en este grupo fue ocho veces superior en comparación con la población general. Se observan con mayor frecuencia localizaciones atípicas y cabe mencionar que la letalidad fue el doble que en la población general (10.3\%-23.5\%)

La TB pulmonar es por mucho la forma más frecuente de afectación ( $85 \%-90 \%$ ) y, entre las formas extrapulmonares, la localización osteoarticular es la tercera en frecuencia por detrás de la pleural y la ganglionar ${ }^{2-4}$.

La TB de la pared torácica (TBPT) es una forma muy infrecuente de presentación, dado que sólo representa $1 \%$ a $5 \%$ de los casos de TB osteoarticular'.

\section{Materiales y métodos}

El paciente concedió su consentimiento informado para la comunicación del caso clínico y el comité de ética institucional su aval. El caso clínico se diagnosticó en la institución de los autores y el cuidado del paciente estuvo a cargo del equipo nefrológico (SL, $A U, P D$ y $A A$ ) en consulta con un infectólogo (ML). Los estudios bacteriológicos para gérmenes inespecíficos incluyeron medios de cultivo para microorganismos aerobios y anaerobios. También se cultivó en medio de Sabouraud para estudio micológico. La búsqueda de Mycobacterium tuberculosis se realizó por técnica de cultivo sólido de Löwenstein-Jensen. La tomografía computarizada se obtuvo con equipo General Electric modelo Óptima y se efectuó la reconstrucción 3D.

\section{Descripción del caso}

Hombre de 42 años procedente de Montevideo, empleado administrativo. Antecedentes personales: ex fumador, hipertensión arterial crónica, sin diabetes; enfermedad renal crónica extrema secundaria a

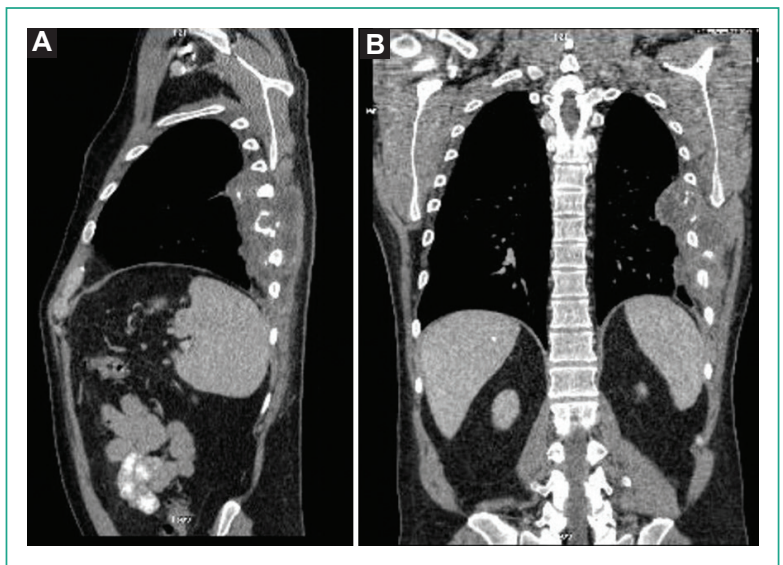

Figura 1. A-B: lesión en pared torácica: lisis de $7^{\circ}, 8^{\circ}$ y $9^{\circ}$ costillas izquierdas, con crecimiento hacia la superficie que compromete tejido subcutáneo y comprime en planos profundos al parénquima pulmonar, que se encuentra indemne.

glomerulopatía crónica sin estudio histológico; en tratamiento de sustitución renal mediante diálisis peritoneal inicial (2013-2015) y hemodiálisis por fístula arteriovenosa nativa (desde 2015 y hasta la actualidad), un cambio de técnica por mala adherencia. Serologías virales para virus de hepatitis B y C negativos, y VIH negativo. Sin antecedente de tuberculosis pulmonar ni extrapulmonar.

Acudió a consulta por tumoración en cara posterior de hemitórax izquierdo, que apareció de forma insidiosa dos meses antes, de límites precisos, con $8 \mathrm{~cm}$ de diámetro, redondeada, lisa, de consistencia gelatinosa, con movilidad limitada por adherencia a planos profundos, sin signos fluxivos locales ni dolor. Niega astenia, adinamia y anorexia los meses previos. No se registra fiebre. El resto de la exploración físico es normal.

Se realizan estudios imagenológicos, en particular tomografía computarizada (Fig. 1) que revela en arcos costales izquierdos $7^{\circ}, 8^{\circ}$ y $9^{\circ}$, sobre la línea axilar posterior, lesiones líticas expansivas de comportamiento quístico, densidad sin homogeneidad, con áreas hipodensas, realce periférico fino y calcificaciones. En el borde externo se extiende a partes blandas adyacentes, donde se identifica una colección de $14 \mathrm{~cm}$ de diámetro que comprime ligeramente al pulmón y muestra una evolución de lesión extrapulmonar. La pleura adyacente se encuentra discretamente engrosada; pequeño granuloma calcificado basal derecho; adenopatías calcificadas laterotraqueales derechas, precarinales y subcarinales. El resto del estudio no muestra alteraciones. De los 
datos paraclínicos destaca el hemograma normal con fórmula leucocitaria conservada, velocidad de eritrosedimentación y proteína $\mathrm{C}$ reactiva en valores dentro de límites normales.

Se realiza drenaje quirúrgico de la colección y se obtiene líquido blanquecino espeso. Cultivo bacteriológico para gérmenes inespecíficos negativo. La búsqueda de gérmenes específicos fue positiva para Mycobacterium tuberculosis complex. El estudio Gen Expert (PCR en tiempo real) fue positivo.

El paciente inicia tratamiento antituberculoso combinado con isoniacida, rifampicina, pirazinamida y etambutol a dosis ajustadas a la enfermedad renal, durante nueve meses. El control fue clínico, imagenológico mediante ecografía y paraclínico con hemograma, función renal y hepática. El paciente no tuvo complicaciones por el tratamiento. Junto con el infectólogo $(\mathrm{ML})$ se decide que el paciente continúe bajo tratamiento dialítico en su centro de diálisis de forma habitual, sin aislamiento respiratorio ni de contacto, ya que el paciente no es bacilífero ni tiene una lesión abierta a piel.

Evoluciona a la remisión clínica de la tumoración que se confirmó con imagen radiológica. Se estableció seguimiento clínico, imagenológico y paraclínico. No tuvo complicaciones por la enfermedad ni por el tratamiento. Luego de dos años continúa en tratamiento hemodialítico regular, sin recidiva de la enfermedad tuberculosa.

\section{Discusión}

Los pacientes bajo tratamiento de reemplazo renal sufren una alteración en la inmunidad tanto celular como humoral que podría explicar una mayor incidencia de infecciones en general y TB. La mortalidad de estos pacientes por tuberculosis es del $23.5 \%$ contra $10.3 \%$ de la población general ${ }^{3}$.

La localización en la pared torácica (TBPT) es una forma muy rara de presentación de la TB, con menos del $0.1 \%$ de todas las formas de TB, y debe diferenciarse de los tumores malignos de la pared torácica. La imagen TC descarta en este paciente la anomalía oncológica y la propagación de una pleuresía tuberculosa purulenta o "empiema de necesidad".

Las series publicadas muestran que la enfermedad prevalece en jóvenes y con mayor frecuencia en el sexo masculino, al igual que este paciente. Aparece como un "absceso frío", dada la ausencia de fiebre, sin elementos fluxivos, como una masa palpable de consistencia fluctuante; las más de las veces es indolora, única y puede comprometer en grado variable a las costillas subyacentes ${ }^{4,5}$.

La terapéutica recomendada es médica y quirúrgica, con particular importancia del drenaje del absceso para lograr curación efectiva y evitar las recaídas ${ }^{4,5}$. Algunos autores proponen, además del drenaje del absceso, la exéresis en caso de compromiso óseo subyacente (costal $)^{6}$. En este paciente, la evolución fue buena y consistió en el drenaje quirúrgico y fármacos antituberculosos combinados por tiempo prolongado.

\section{Conclusiones}

Se registra una incidencia elevada de casos nuevos y recaídas de TB en el medio de 28.6 por 100,000 habitantes; la incidencia en pacientes en tratamiento sustitutivo renal es ocho veces mayor y de éstos la mayoría reside en Montevideo. Estos datos sugieren que debe mantenerse un alto índice de sospecha para determinar el diagnóstico. La mortalidad en diálisis por tuberculosis es el doble respecto de la población general. La expresión clínica y radiológica de la TB en este paciente es similar a la de las presentaciones de las escasas series notificadas. El tratamiento antibiótico combinado y el drenaje quirúrgico temprano son las indicaciones terapéuticas.

\section{Agradecimiento}

Los autores agradecen al paciente por permitir la presentación de su caso clínico y al departamento de imagenología de la Casa de Galicia por el uso de las imágenes.

\section{Conflicto de intereses}

Los autores declaran que no existe conflicto de intereses.

\section{Responsabilidades éticas}

Protección de personas y animales. Los autores declaran que para esta investigación no se han realizado experimentos en seres humanos ni en animales.

Confidencialidad de los datos. Los autores declaran que han seguido los protocolos de su centro de trabajo sobre la publicación de datos de pacientes.

Derecho a la privacidad y consentimiento informado. Los autores declaran que en este artículo no aparecen datos de pacientes. 


\section{Bibliografía}

1. OMS. Informe mundial tuberculosis 2019. [citado 15 mayo 2019]. Disponible en: https://www.who.int/tb//global_report/es/

2. Comisión Honoraria de Lucha Antituberculosa y enfermedades prevalentes. Informe Tuberculoso 2018. [citado 15 mayo 2019]. Disponible en http://chlaep.org.uy/wp-content/uploads/2019/05/Situaci\%C3\%B3n-Tuberculosis-Uruguay-2018.pdf

3. Baccino C, González C, Borges PL, Garau M, Rodríguez J, Noboa O. Tuberculosis en pacientes en diálisis en Uruguay. Rev Méd Urug. 2020;36(2):140-5.
4. Benjelloun H, Morad S, Zaghba N, Bakhatar A, Yassine N, Bahlaoui A. Les abcès froids pariétaux thoraciques chez les sujets immunocompétents. Pan Afr Med J. 2015:20;161. doi: 10.11604/ pamj.2015.20.161.5773

5. Tanaka S, Aoki M, Nakanishi T, Otake Y, Matsumoto M, Sakurai T, et al. Retrospective case series analysing the clinical data and treatment options of patients with a tubercular abscess of the chest wall. Interact Cardiovasc Thorac Surg. 2012;14(3):249-52.

6. Paik HC, Chung KY, Kang JH, Maeng DH. Surgical treatment of tuberculous cold abscess of the chest wall. Yonsei Med J. 2002;43(3):309-14 